\title{
A Decision-Making Process for Selecting of Lean Tools Implementation Methods by Means of Analytical Hierarchy Process in Health Center
}

\author{
Seyed Navid Seyedia*, Saeed Hakimia, Hadi Badri Ahmadia, Pouyan Rezvana, Mozghan Izadifara \\ ${ }^{a}$ Department of Manufacturing and Industrial Engineering, Facility of Mechanical Engineering, University Teknologi Malaysia, 81310 UTM Johor \\ Bahru, Johor, Malaysia
}

*Corresponding author: Seyedi.navid@gmail.com

\section{Article history}

Received :4 April 2013

Received in revised form :

25 July 2013

Accepted :15 October 2013

\begin{abstract}
Decision making is contemplated as a serious task in management context and it becomes more challenging when appropriate alternatives should be selected among various options based on some criteria. Analytical Hierarchy Process (AHP) is one of the multi-criteria decision making methods, which is widely used in management science because of its reliable and acceptable performance. In this study, a novel execution of adjusted AHP in decision making was utilized in a case study in Iran in order to find the best method for application of lean concept among alternatives. Previous-mentioned alternatives are consulting, college student, and internal human resource. Case study results demonstrated that using consultants for carrying out lean tools is the best method. The degree of consistency is satisfactory and proved the accuracy and correction of application of AHP in finding the best method for implementation of lean tools.
\end{abstract}

Keywords: Analytical Hierarchy Process (AHP); lean tools; lean assessment; decision making; adjusted AHP

(c) 2013 Penerbit UTM Press. All rights reserved.

\subsection{INTRODUCTION}

Recently, the way is being paved to link the manufacturing concepts to other aspects like service sectors. In this sense, lean concept is a tool set, a management system, and a philosophy that can change the way, organizations are categorized and managed (Radnor, 2010). Nowadays, Hospitals and health centers discovered the advantages of lean implementation like removing duplications, decreasing waiting time, and waste reduction (NHSIII, 2007). Therefore they try to get involved in group of organizations that improve their position by applying lean approaches. In addition, Lean is a system for strengthening hospital organizations in terms of long term-reduction of costs and risks while facilitating growth and expansion. Moreover, it is used to help different hospital departments to work together for the benefit of patients.

The rest of the paper is organized as follow. The AHP method and lean approach is described in section 2, experimental results from the case study is presented in chapter 3 , chapter 4 is about reporting and discussing the results, and the last chapter is conclusion.

\subsection{LITERATURE REVIEW}

Lean concept originated from the Toyota Motor company, Lean (also is called Toyota Production System, TPS) is taken into account as a detailed alternative to the traditional method of mass production and batching principles for increasing operational efficiency, quality, speed and cost (Holweg, 2007). The development of Lean Production has been described greatly and will not be discussed here (Fujimoto, 1999; Hines, Holweg, \& Rich, 2004; Holweg, 2007; Ohno, 1988; Womack, Jones, \& Roos, 1990).

Historically, Lean was introduced to healthcare for the first time in UK in 2001 and in the USA in 2002. However, the literature proposes considerable variability in the application of Lean with distinctions in approach and scope. Specifically, more of healthcare providers are interested towards small enclosed projects that create 'pockets of best practice' instead of selecting a firm or system-wide approach (Brandao de Souza, 2009; Radnor 2010), although Spear (2005) claims that "[..] in healthcare, no company has completely institutionalized to Toyota's level the competence to design work as experiments, modify work through experiments, share the scientific result through frequent experiments and develop people as experimentalists".

According to Guthrie (2006); Radnor, Walley, Stephens, \& Bucci, (2006), Fillingham, (2008) and Young \& McClean, (2008), lean implementation has had a significant impact in healthcare sector. In Scotland Cancer Treatment organization, customers waiting time for first appointment decreased from 23 to 12 days. Bolton improving care systems (lean), in royal Bolton hospital, affected the direct savings of $£ 3.1 \mathrm{~m}$. In addition, death rate for patients fell by one third. Lean techniques in Pittsburgh General 
Hospital changed the procedure for intravenous line insertion and resulted $90 \%$ drop in the number of infections after 90 days.

AHP is a multicriteria decision making method for prioritizing the alternatives in taking the multiple criteria into account. Developed by Saaty (1977 and 1996), AHP has the advantage of pair wise comparisons to attain a ratio scale of measurement. Ratio scales are compared among alternatives and make it possible to measure both tangible and intangible factors (Liberatore and Nydick, 2008). Kokangul and Susuz (2009) argued that AHP estimates the additive utility weight that best suits the initial information which decision makers presented. It provides a significant way to measure and merge tangible and intangible criteria in any decisions. Wanichpongpan and Gheewala (2007), Hermann et al. (2007) and Kim et al. (2009) also applied AHP in Life Cycle Assessment (LCA) as decision support or multi-criteria analysis tool.

\subsection{PROBLEM STATEMENT}

In 1972, RAHA health center was established in Karaj, Iran in order to play a significant role in providing health and well-being in its distinct area. The strategy of organization is to create a physical, mental, and social health for community.

Recently, management of RAHA health center decided to implement lean tools, which is on the lime light in various fields, to obtain competitive advantage. The purpose is selecting among Consulting (A), College students projects (B), and internal human resource $(C)$ as alternatives, which had been used by other health centers for implementation of lean tools. These health centers are similar to RAHA in different fields such as managerial approaches, motivation etc.; subsequently the effect of mismatch among study conditions were minimized.

In the first method, the health center would be assessed by expert consulting organizations. The advantage of this method is time reduction in fulfillment of tools, however, higher cost is considered as disadvantage of this method. The second method is the invitation of the college students to use lean tools implementation as their projects, which leads to significant cost reduction which takes longer time. Applying internal staffs for implementation of lean tools by training and manage them, is the last method. The feature of this method was lower cost in comparison with consulting but higher in proportion to students. The main advantage of this method is remaining the knowledge and skill as an asset in the organization.

Lean assessment was done in each health center through five lean tools by specific survey questionnaires to form criteria for decision making to gain the best method.

Mentioned lean tools are as follows:

1- Waste exists in every process in every organization. All activities can be categorized into 3 elements: Waste (not value added work), Incidental work (not necessarily value added work), and Actual work (value added work). The seven types of wastes which were described by Toyota as the 7 deadly wastes are: Overproduction, Waiting, Transportation, Over processing, Inventory, Motion, and Correction (of defects).

2- As a lean assessment tool Kaizen leads to standardize process and activities through which it results to waste elimination. Even small continuous improvement and standardization has a huge effect on organization performance in long time. Kaizen involves participation of different levels of people in an organization from CEO till workforce in the lowest level of organization chart.

3- The Kanban method is an approach to incremental, evolutionary process and systems change for organizations. It uses a work-in-progress limited pull system as the core mechanism to expose system operation (or process) problems and stimulate collaboration to continuously improve the system.

4- $\quad 5 \mathrm{~S}$ is the name of a workplace organization method that uses a list of five Japanese words. The five components of $5 \mathrm{~S}$ are defined as sort, set, shine, standardize, and sustain. $5 \mathrm{~S}$ is a method that reduces waste in work environment through, better workplace organization, visual communication, and general cleanliness.

5- Mistake-proofing known as poka-yoke, is the use of process and design features to prevent errors or the negative impact of errors.

The study purpose is to find the best suitable alternative from these mentioned methods (A, B , and C), based on five primary criteria in terms of lean tools.

\subsection{METHODOLOGY}

Table 1 shows the survey questionnaires' results, which are the scores of each lean tool in terms of each alternative, A, B, and C. It should be mentioned that all questionnaires were designed based on lean assessment tools in health centers. The lean assessment was executed based on the scores among 1 to 9 because it should be coordinated according to standard preference scale for pair wise comparison (Table 2).

Table 1 The lean assessment scores

\begin{tabular}{cccc}
\hline & Consulting (A) & Student $(\mathbf{B})$ & Staff $(\mathbf{C})$ \\
\hline Waste & 8 & 2 & 3 \\
Kaizen & 4 & 7 & 9 \\
Kanban & 7 & 5 & 7 \\
$5 S$ & 3 & 2 & 4 \\
Poka-yoke & 3 & 6 & 3 \\
\hline
\end{tabular}

Table 2 Preference scale for pairwise comparisons

\begin{tabular}{lc}
\hline \multicolumn{1}{c}{ Preference Level } & $\begin{array}{c}\text { Numeric } \\
\text { Value }\end{array}$ \\
\hline Equally preferred & 1 \\
Equally to moderately preferred & 2 \\
Moderately preferred & 3 \\
Moderately to strongly preferred & 4 \\
Strongly preferred & 5 \\
Strongly to very strongly preferred & 6 \\
Very strongly preferred & 7 \\
Very strongly to extremely preferred & 8 \\
Extremely preferred & 9 \\
\hline
\end{tabular}

AHP uses paired comparison based on the idea that a complicated subject can be effectively tested if it is hierarchically divided into its elements. After that, the elements are compared with each other. To obtain pair wise comparison matrix for every criterion the weighting average method was used, where the cost weight was 0.3 and lean weight was 0.7 . These weights are adopted according to management idea depends on organization 
plans and allocated financial investment. By adjusting the cost of each alternative according to the score scale between 1 to 9 , the cost scores of method $\mathrm{A}, \mathrm{B}$ and $\mathrm{C}$ were considered 8, 2 and 6 respectively. The weighting average between cost and the lean assessment score resulted the pair wise comparison matrix as shown in the figure 1 .

\begin{tabular}{|c|c|c|c|c|c|c|c|}
\hline \multicolumn{4}{|c|}{ Waste } & \multicolumn{4}{|c|}{ Kaizen } \\
\hline $\bar{A}$ & 1 & 4 & 2.2667 & $\bar{A}$ & 1 & 1.6 & 0.7111 \\
\hline$B$ & 0.25 & 1 & 0.5667 & $B$ & 0.625 & 1 & 0.6444 \\
\hline$C$ Lc & 0.44121. & .7647 & $7 \quad 1$ & $C$ & 1.4063 & 1.5517 & 1 \\
\hline \multicolumn{4}{|c|}{ Kanban } & \multicolumn{4}{|c|}{$5 S$} \\
\hline $\bar{A}$ & 1 & 2.1 & $\begin{array}{ll}8 & 1.1]\end{array}$ & $\bar{A}$ & 1 & 2.25 & 0.925 \\
\hline B & 0.4587 & 1 & 0.6 & $B$ & 0.4444 & 1 & 0.45 \\
\hline$C$ & Lo.9091 & 1.66 & 671 & C & 1.0811 & 2.2222 & 1 \\
\hline \multicolumn{8}{|c|}{ Poka-yoke } \\
\hline & & $\bar{A}$ & 1 & .55 & $0.1]$ & & \\
\hline & & $B$ & 0.6452 & 1 & 1.5 & & \\
\hline & & $C L_{0}$ & 0.9091 & 666 & $1]$ & & \\
\hline
\end{tabular}

Figure 1 Pair wise tables for 5 lean tools

Determining which method was preferred in hierarchy for each of the five criteria was the next step that is referred in AHP as Synchronization. The synchronization in this case was performed by means of normalizing the previous pair wise matrices; table 3 presents the criteria preference matrix.

Table 3 The preference matrix for criteria

\begin{tabular}{|c|c|c|c|c|}
\hline Waste & Kanban & Ka izen & $5 s$ & Poka - yoke \\
\hline $\mathrm{A}[0.5913$ & 0.3391 & 0.4265 & 0.3989 & $0.3930]$ \\
\hline \begin{tabular}{l|l} 
В & 0.1478
\end{tabular} & 0.2402 & 0.2074 & 0.1827 & 0.3267 \\
\hline C $[0.2609$ & 0.4207 & 0.3661 & 0.4184 & 0.2803 \\
\hline
\end{tabular}

Ranking the criteria by means of normalizing technique which means the respective weight or importance of each criterion, should be determined and ranked subsequently. The outcome of normalizing approach and ranking is shown in table 4.

Table 4 The criteria ranks

\begin{tabular}{cccccc}
\hline & Waste & Kaizen & Kanban & 5S & $\begin{array}{c}\text { Poka- } \\
\text { yoke }\end{array}$ \\
\hline Criteria & & & & & \\
ranks & 0.464591 & 0.319682 & 0.058099 & 0.116337 & 0.041291 \\
\hline
\end{tabular}

The last ranking obtained from multiplying preference matrix and criteria ranks. Finally, Consistency index was calculated to suggest some explanations on how serious is violations of numerical and transitive consistency. The consequences could be used to search additional information and re-examine the data used in building the scale in order to improve consistency. It is important to check the consistency in the pair wise comparison matrix and the validation of the AHP.

\subsection{RESULTS AND DISCUSSION}

According to results, Consulting (A) gains the higher weight equal to 0.470514 , and internal human resource (C) stands in the second place with the weight of 0.3372 , College students projects (B) is the worst decision by the weigh 0.19227 . Table 5 presents the degree of consistency for both criteria ranking matrix and criteria preference matrix for each alternative:

Table 5 The degree of consistency for entire AHP

\begin{tabular}{lc}
\hline Pair wise matrix name & Degree of consistency \\
\hline criteria preference matrix & 0.0634 \\
Waste matrix & 0.0001 \\
kaizen matrix & 0.0132 \\
Kanban matrix & 0.0029 \\
5S matrix & 0.0008 \\
Poka yoke matrix & 0.0540 \\
\hline
\end{tabular}

By comparing the consistency degree results, it is obvious all of them are less than 0.1 which is an acceptable ratio; consequently the degree of consistency is satisfactory and AHP result is meaningful.

\subsection{CONCLUSION}

In this paper, the lean tools assessment was considered as criteria to select the best decision among three methods including consulting, students, and staff for implementation of lean concept in health center. An adjusted AHP method was used and cost factors that are regarded as significant factors for management were involved in establishing preference matrix by means of weighting average method. Eventually, consulting was chosen as the preferred method for implementation of lean concept in the health center. The precision and correctness of AHP method was reflected by consistency indices and entire results were satisfactory. Implementation of lean tools in other industries by using AHP model applied in this research could be a good direction for future studies.

\section{References}

[1] Brandao de Souza, L. 2009. Trends and Approaches in Lean Healthcare. Leadership in Health Services. 22(2): 121-139.

[2] Fillingham, D. 2008. Lean Healthcre: Improving the Patient's Experience. Chichester: Kingsham Press.

[3] Fujimoto, T. 1999. Organisational for Effective Product Development The Case of the Global Automobile Industry. Boston: Harvard University Graduate School of Business Administration.

[4] Guthrie, J. 2006. The Joys of a Health Service Driven by Toyota. Financial Times.

[5] Hermann, B. G. and C. Kroeze, et al. 2007. Assessing Environmental Performance by Combining Life Cycle Assessment, Multi-Criteria Analysis and Environmental Performance Indicators. J. Clean. Prod. 15: 1787-1796.

[6] Hines P. and et al. 2004. Learning to Evolve. A Review of Contemporary Lean Thinking. International Journal of Operations and Production Management. 24(10): 994-1011. 
[7] Holweg, M. (2007). The Genealogy Of Lean Production. Journal of Operations Management. 25: 420-437.

[8] Kim, J. and Y. Hwang, et al. 2009. An Assessment of the Recycling Potential of Materials Based on Environmental and Economic Factors; Case Study In South Korea. J. Clean. Prod. 17: 1264-1271.

[8] Kokangul, C.A. and Z. Susuz. 2009. Integrated Analytical Hierarch Process and Mathematical Programming to Supplier Selection Problem with Quantity Discount. Appl. Math. Model. 33: 1417-1429.

[9] Liberatore, M. J. and L. Robert. 2008. The Analytic Hierarchy Process in Medical and Health Care Decision Making: A Literature Review Nydick 1 .

[10] Ohno, T. 1988. The Toyota Production System: Beyond Large-Scale Production. Portland: Productivity Press.

[11] Radnor, Z. J. 2010. Review of Business Process Improvement Methodologies in Public Services. Advanced Instuite of Management.
[12] Radnor, Z. J. and P. Walley, et al. 2006. Evaluation of the Lean Approach to Business Management and Its Use in the Public Sector. Government Social Research.

[13] Saaty, T. L. 1996. The Analytic Hierarchy Process. RWS Publications, Pittsburgh, PA.

[14] Saaty, T. L. 1977. A Scaling Method for Priorities In Hierarchical Structures. Journal of Mathematical Psychology. 15: 234-281.

[15] Spear, S. 2005. Fixing Health Care From the Inside. Harvard Business Review. 83(9): 78-91.

[16] Wanichpongpan, W. and S.H. Gheewala. 2007. Life Cycle Assessment as a Decision Support Tool for Landfill Gas-To Energy Projects. J. Clean. Prod. 15: 1819-1826.

[17] Womack, J. P. and D. T. Jones, et al. 1990. The Machine that Changed the World. New York: Rawson Associates.

[18] Young, T. P. and S. I. McClean. 2008. A Critical Look at Lean Thinking in Healthcare. Quality \& Safety in Health Care. 17: 382-386. 